FILOZOFIA

Roč. 75, 2020, č. 3

DOI: https://doi.org/10.31577/filozofia.2020.75.3.3

\title{
THE ROLE OF SOCRATES, LYSIS, AND MENEXENUS IN PLATO'S LYSIS
}

GABRIEL EVANGELOU, University of Cyprus, Department of Classics and Philosophy, Nicosia, Cyprus

\begin{abstract}
EVANGELOU, G.: The Role of Socrates, Lysis, and Menexenus in Plato's Lysis FILOZOFIA, 75, 2020, No 3, pp. $195-211$

The aim of this study is to demonstrate that the value of the Lysis does not lie in

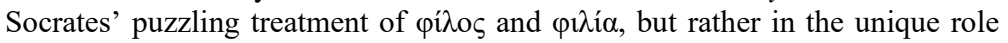
that both Socrates and the other two main interlocutors, Lysis and Menexenus, assume in this Platonic dialogue. In the Lysis, Socrates plays the role of the sophist who uses errant logic, but with whom the young men are so infatuated that they simply agree with his every statement. Their inability to display critical thinking by challenging his flawed arguments constantly forces Socrates to revert to the role of the philosopher who refutes the points that he, himself, had just raised. The dialogue thus functions as a warning against blindly trusting the education of youths to sophists and potentially as an exercise for Plato's students to detect problematic argumentation and to practise arguing against it.
\end{abstract}

Keywords: Plato - Socrates - Lysis - Philia - Sophists - Aporia - Deception

The perplexity of the Lysis has been a topic of considerable debate. Throughout the dialogue, the reader is given the impression that Socrates is attempting to provide a definition of ' $\varphi$ í $\lambda \circ \varsigma^{\prime \prime}$ by asking the two teenagers, Lysis and Menexenus, a series of questions. ${ }^{2}$ Nevertheless, before reaching a conclusion, their philosophical discussion

\footnotetext{
${ }^{1}$ The scope of the Lysis has been heavily contested. While most scholars, such as Price $(1990,1)$ and El Murr $(2014,3)$, consider $\varphi \imath \lambda i ́ \alpha$ to be its main topic of discussion, Nichols $(2006,1)$ argues

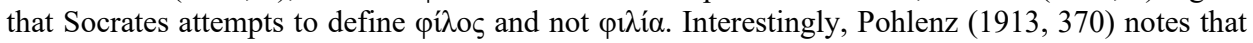
the dialogue deals chiefly with $\pi \alpha \iota \delta$ เò $\varsigma$ है $\rho \omega \varsigma$, a view which was vehemently rejected by von Arnim $(1914,60)$. Similarly, Annas $(1977,551)$ maintains that through the Lysis Plato does not attempt to provide a comprehensive account of $\varphi \imath \lambda i \alpha$, since he is mainly interested in discussing "intellectually attractive paradoxes". However, the fact that Socrates also examines Lysis' $\varphi \imath \lambda i \alpha$ with his parents shows that even though he was predominately interested in the constituent elements of a pítos, his discussion also touched upon common perceptions of $\varphi \imath \lambda i \alpha$. For a definition of $\varphi \imath \lambda i^{\alpha} \alpha$ in the ancient

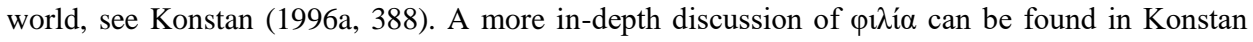
(1996b, 71 - 94, 1997).

${ }^{2}$ Considering the fact that in the Lysis Socrates discusses the conditions under which one can be regarded as $\varphi$ í $\lambda \mathrm{o} \varsigma$ to another person, it would follow that the Lysis would be the primary source of Plato's views of $\varphi \imath \lambda i \alpha$. Nevertheless, a serious treatment of $\varphi \imath \lambda i \alpha$ is absent from the Lysis and thus
} 
is interrupted by the teenagers' guardians. While far from the only Platonic dialogue to end in aporia, ${ }^{3}$ or without proper use of the Socratic elenchus, ${ }^{4}$ it is the overall purpose of the dialogue that has led many scholars to question its value as well as its authenticity. ${ }^{5}$ More importantly, Socrates' arguments are atypically weak to the point that a significantly different Socrates arises before the readers' eyes compared to Plato's later works. ${ }^{6}$ Socrates not only uses errant logic that both Lysis and Menexenus fail to detect, he is the one who stresses the fallacy in his own arguments. This paper aims to answer an important question: what role do the main interlocutors play, and subsequently, what is the purpose of the dialogue? By investigating Socrates' arguments as well as Lysis and Menexenus' responses to them, it will attempt to show that, through the three main speakers, Plato demonstrates how easy it is to manipulate young men, who were so impressionable and willing to accept the statements of sophists as fact, that they were unable to form their own opinions. The discussion will argue against scholars who, in the last few decades, have been at pains to defend the

the study of the Phaedrus, the Symposium, and the Laws is necessary to discern the Platonic account of $\varphi \imath \lambda i ́ \alpha$.

${ }^{3}$ For instance, Euthyphro, Charmides, Laches. Wolfsdorf $(2007,237)$ argues that the fact that the dialogue ends in aporia does not prevent the reader from being able to observe Socrates' account of $\varphi \imath \lambda i ́ \alpha$. ${ }^{4}$ Vlastos $(1991,128)$ notes that the elenchus is absent in the Lysis as much as in the Hippias Major and the Euthydemus.

5 The possibility that the Lysis is spurious was introduced in the $19^{\text {th }}$ century by Ast $(1816,428-$ 434), and Socher $(1820,137-144)$ and Cholava $(1858,793-802)$. Their view was, nonetheless, rejected. Lutoslawski (1897) chooses a different approach. He refrains from rejecting the Lysis as spurious, but does not state that he regards it as an authentic Platonic dialogue either. Taylor (1949, 64) has persuasively argued in favour of the dialogue having been written by Plato by stressing the many references to it in Aristotle's book eight and nine of the Nicomachean Ethics. Price $(1990,1)$ also points out that the Lysis is Aristotle's "starting-point" in both the Nicomachean and the Eudemian Ethics. Glidden $(1981,54$ - 55) expresses a similar view by noting that Plato's dialogue "stands as a prolegomenon for some future study", including the Symposium and the Phaedrus. Penner and Rowe (2005, xii) maintain that the Lysis "sets the agenda" for the Symposium, the Phaedrus, and Aristotle's discussion of $\varphi$ i $\lambda$ í $\alpha$ in his Ethics. Conversely, divergency of opinion can be observed in the significance of the Lysis as a philosophical discussion of $\varphi$ í $\lambda \circ \varsigma$ and $\varphi \imath \lambda i ́ \alpha$. According to Versenyi $(1975,186)$, the playful character of the dialogue does not prevent Socrates from raising valid points

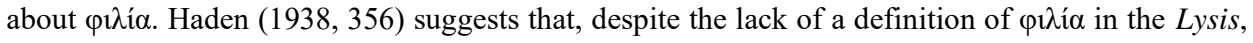
the discussion between Socrates, Lysis, and Menexenus and the study of these characters offers valuable insight into Plato's views of $\varphi \imath \lambda i \alpha$. Bolotin (1979, $61 \mathrm{n} .86)$, on the other hand, interprets Socrates' arguments as an exploration of the possibility that $\varphi \imath \lambda i^{\prime} \alpha$ does not exist. Similarly, Vlastos $(1973,8-9)$ considers it a failure and Guthrie $(1975,143)$ asserts that Plato would agree that the Lysis cannot be considered "a success".

${ }^{6}$ A prime example would be Hippias Major, another one of Plato's early dialogues that fails to

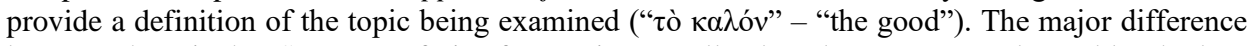
between them is that Socrates refrains from using equally absurd arguments and, notably, the language that he employs in the dialogue does not betray an intention to warn his audience against trusting his own words. Mackenzie $(1985,89)$ also observes the extent to which Plato's early dialogues differ from his later works. 
dialogue by trying to provide an explanation for each argument that Socrates makes however problematic it may be. ${ }^{7}$

\section{Socrates' attempt to deceive the reader}

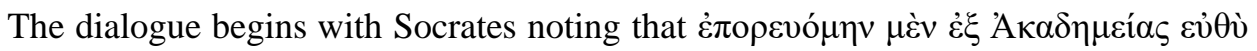
$\Lambda$ straight to the Lyceum along the road that runs outside the wall, under the wall itself", $203 \mathrm{~A} 1-2) .{ }^{8}$ At first glance, his remark seems rather innocent; it could simply be a way to set the scene. However, as Planeaux has observed, the path that Socrates chose did not take him 'directly'/'straight' to the Lyceum and this must have been common knowledge to any Athenian, including the reader of the Lysis. ${ }^{9}$ The fact that Socrates seemingly tries to mislead his reader, rather than his interlocutors, from the very first sentence of the dialogue gives the impression that Plato intends to warn his reader that Socrates is not to be trusted, at least not fully. ${ }^{10}$ The careful reader, who realises that Socrates is willing to bend the truth, is expected to pay closer attention to Socrates' statements throughout the dialogue. A few lines later, Socrates notes that he

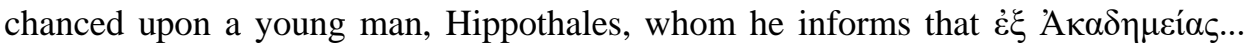

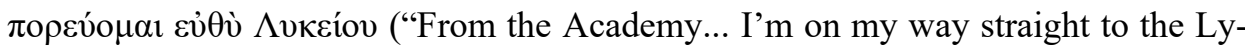
ceum”, 203B2). Not only does he repeat the first sentence almost word for word, but he claims again, something that Hippothales was surely aware to be a half truth, as Socrates was not in fact heading $\varepsilon \dot{v} \theta \dot{v}$ to the Lyceum. The repetition of the statement in just a few lines draws the reader's attention, likely in an effort to alarm him/her further about Socrates' intentions with the conversation that is to follow. At the same time, Hippothales has the opportunity to question the validity of Socrates' remark, but

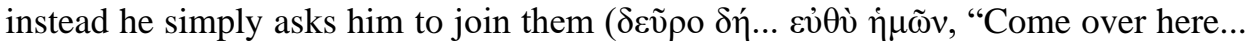
straight to us", 203B3). This is the third time that the adverb củ $\theta \dot{v}$ is used in just eight

\footnotetext{
${ }^{7}$ Wolfsdorf $(2007,235)$ observes the tendency in modern discussions of the Lysis to begin with a defence of the dialogue. For examples of modern scholars defending the dialogue, see Dirlmeier (1931, 56 - 58), Hoerber (1959, 19 - 22), Bosch-Veciana (1998). Penner and Rowe (2005) develop a remarkable, though ultimately unsuccessful, effort to defend Socrates' arguments in the Lysis. They admit in several occasions (e.g. 68, 71) that there are "gaps in Socrates' argument" that "certainly baffle us for a while" or that "Socrates' argument commits him to something blatantly false". ${ }^{8}$ All translations from the Lysis are from Penner and Rowe (2005).

${ }^{9}$ Planeaux $(2001,60)$ stresses that $\varepsilon \dot{v} \theta \dot{v}$ "to the Lyceum from the Academy would have been through the Demosian Sema, through the Dipylon Gates, along the Eridanus, past the ó $\gamma o$ ó , and through the Diochares Gates. Instead, Socrates swings out of his way, around the ö $\sigma \tau v$, and approaches the Lyceum from the north." In contrast, Hetherington (2009, $151-160)$ argues against the possibility that this episode suggests that Socrates should be perceived as an unreliable narrator.

${ }^{10}$ Planeaux $(2001,61)$ interprets Socrates' opening statement as invitation to "our skepticism". Penner and Rowe $(2005,4)$ point out that a similar warning about sophists can be found in the beginning of the Protagoras.
} 
lines. If the dialogue was indeed written by Plato partly as an exercise for his students, ${ }^{11}$ while the careful student would have seen through Socrates' disingenuousness from the beginning, the third cuvov would help even the less gifted student to detect Socrates' attempt at misinformation.

\section{The explicit and implicit presence of sophists}

As the dialogue progresses, Socrates leaves Hippothales to talk with Lysis and Menexenus. The two young men are also at the recently-built wrestling school, where they are being educated by Miccus, a sophist, who, according to Socrates, ov̉ $\varphi \alpha \tilde{\nu} \lambda \delta^{\prime} \gamma \varepsilon$

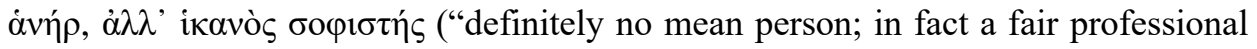
when it comes to wisdom", 204A6-7). ${ }^{12}$ Therefore, the existence of a sophist in the setting of the Lysis is introduced from the beginning of the dialogue. When Socrates' discussion with the teenagers commences, prima facie a 'competent' (ikavò $\varsigma$ ) sophist, Miccus, is replaced with a non-sophist philosopher, Socrates. However, as the discussion reveals later on, Socrates is by no means better than a sophist. ${ }^{13}$

Plato's attitude towards sophists and the tactics that they employ is, by and large, consistent throughout his works: ${ }^{14}$ he is highly critical of them because they lack consistency, they focus on appearances (Soph. 236B4-C8) and, unlike Socrates, are not interested in the discovery of truth. What matters to them is popular opinion ${ }^{15}$ and the ostensibly true, since their ultimate goal is winning every debate (Gorg. 472B). Plato chastises them for their eristics and for employing the art of antilogic in their debates. ${ }^{16} \mathrm{He}$ also expresses concerns over rhetoric, because of the disregard of those who use it for what is truthful, right or wrong and their indifference to the education of other people (Gorg. 454D - E, 455A, 465B, Euthyd. 272A7 - B1). He portrays

\footnotetext{
${ }^{11}$ This view has been expressed by Bury $(1910,273)$, who suggests that Plato's early dialogues "are little more than preliminary exercises in elementary dialectic".

${ }^{12}$ Penner and Rowe $(2005,4)$ maintain that the reference to Miccus as a "sophist" is "used in a purely descriptive way".

${ }^{13}$ Ludwig (2010, 142 - 143) draws parallels between Socrates' and the sophists' argumentation. Glidden $(1981,45)$ observes that in 222E1 Socrates gives the impression of "a sophist in a courtroom”. Bosch-Veciana (1998, 116), in Socrates' discussion of justice (207D1) and wisdom (207D2), detects "a criticism of sophistics". Conversely, Penner and Rowe $(2005, \mathrm{xi})$ argue that even though modern readers may get the impression that in the Lysis Socrates acts like "a kind of sophist", such a view should be rejected, since defeating his interlocutors would be a "silly exercise". Therefore, the possibility of Socrates taking the role of a sophist has been considered, though without having been properly explored in scholarship.

${ }^{14}$ Irwin $(1995,573)$ stresses Plato's efforts to draw a sharp distinction between Socrates and the sophists.

${ }^{15}$ In Rep. 493A6 - 9 Plato expresses his disapproval of the sophists for presenting common beliefs as wisdom.

${ }^{16}$ For the significant differences between eristic and antilogic, see Kerferd (1981, 62 - 67). The dangers of the use of antilogic, especially by young men, is further stressed by Plato in Rep. 539B2 - 7 .
} 


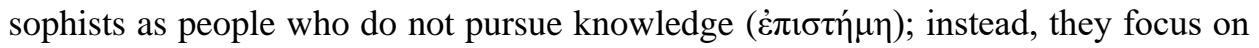
opinion ( $\delta \delta \xi \alpha)$ and on giving the impression to others that they are knowledgeable. ${ }^{17}$ While sophists feature prominently in Plato's dialogues, including the Protagoras, the Gorgias, and the Sophist, the most striking parallels with the Lysis can be found in the Euthydemus. In both the Lysis and the Euthydemus, the tricks that sophists tend to use are prevalent. The Socrates of the Lysis greatly resembles the two sophists of the Euthydemus, Euthydemus and Dionysodorus, who unlike Protagoras and Gorgias, are portrayed as charlatans with no interest in educating youths. In fact, even though they profess to teach virtue (Euthyd. 273D), their dialogue with Cleinias, does not benefit the young man in any way. ${ }^{18}$ They do not attempt to offer a valuable lesson to him, but to demonstrate their superiority by refuting his claim, irrespective of the answer that he provides (Euthyd. 273E). They even admit that they phrase their questions to their interlocutor in such a way that they do not leave him "any room to escape" (ö $\varphi v \kappa \tau \alpha$, Euthyd. 276E). As Grady points out, until Socrates intervenes, the two sophists are evidently successful at persuading Cleinias by "employing set arguments grounded in double meanings and verbal ambiguities designed to confound and confuse an interlocutor". ${ }^{19}$ Their absurd arguments ${ }^{20}$ are equally effective on the sophists' followers: when Cleinias gives the wrong answer to a trick question that Euthydemus asks him, Dionysodorus points out that he is incorrect and their followers begin to laugh and applaud them (Euthyd. 276C - D). ${ }^{21}$ Thus, through the dialogue Plato underlines the dangers that sophistry poses, especially on young and naive men. ${ }^{22}$ The only major difference between Socrates in the Lysis and the sophists in his other dialogues is that Socrates does not ask for payment from Lysis and Menexenus. ${ }^{23}$ In this

${ }^{17}$ O'Grady $(2008,53)$ notes that Plato does not see any "pedagogical value" in rhetoric.

${ }^{18}$ As the discussion that follows will show, Socrates' dialogue with Lysis and Menexenus ends with the two teenagers not having gained any knowledge on the topic of what a pí $\lambda$ os is.

${ }^{19}$ O'Grady $(2008,124)$. Similarly, in the Lysis the teenagers are constantly persuaded by Socrates throughout the dialogue to the point that Socrates is forced to intervene by pointing out the fallacy in his argumentation.

${ }^{20}$ On the absurdity of the sophists' argumentation, see also Sermamoglou-Soulmaidi (2014, 90, 110, 116).

${ }^{21}$ It is worth stressing that even though Socrates also constantly corrects Lysis and Menexenus, he does not attempt to ridicule them.

${ }^{22}$ Lamb $(1952,375,376)$ also observes an effort to expose the sophists' tactics and argues that, through Socrates, Plato attacks Euthydemus and Dionysodorus for preying on young men who are being deceived by their "spurious argumentation" and "verbal tricks".

${ }^{23}$ Harrison (1964, 191 n.44) provides a list of Plato's references to sophists receiving payment for their services. Nevertheless, as Blank $(1985,6)$ points out, Plato's strong disapproval of the sophists' practise of teaching for money is not abundantly clear in his dialogues. 
regard, Socrates is indubitably not a typical sophist. ${ }^{24}$ Nevertheless, his argumentation is equally sophistic, thereby becoming, for the most part, a sophist. ${ }^{25}$

The view of a radically different Socrates in the Lysis had already been expressed by Diogenes Laertius:

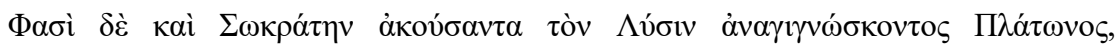

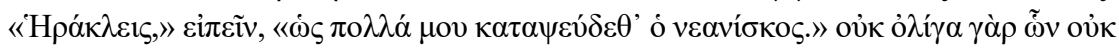

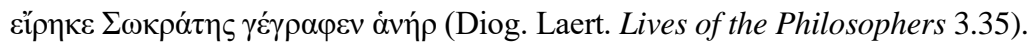

They say that when Plato heard Socrates reading the Lysis, he said "Dear God, how many lies has the young man been saying about me!" For Socrates never said many of the things that the man has written.

While this passage is frequently quoted in discussions of the Lysis, its significance is not recognised by modern scholars who try to defend Socrates' arguments, in order to argue that the dialogue is a valuable source in the study of Plato's account of $\varphi \imath \lambda i \alpha^{26}{ }^{26}$ Even though there is no doubt in scholarship that the dialogue was not written while Socrates was still alive and that this quote is an apparent exaggeration, ${ }^{27} \mathrm{it}$, nonetheless, conveys a certain message: the Socrates of the Lysis differs enormously from the historical Socrates, arguably more than the Socrates of any other extant Platonic dialogue.

Lysis and Menexenus portrayed as gullible young men

Throughout the dialogue, neither Lysis nor Menexenus displays independent thinking. ${ }^{28}$ Most of their answers are notably short. They do not contribute to the discussion in any substantial way, as they consistently agree with Socrates and refrain from

${ }^{24}$ Tell $(2009,13)$ notes that earning money from teaching is one of the basic characteristics of sophists in Plato's dialogues.

${ }^{25}$ Even though Planeaux $(2001,66)$ also stresses the significance of Plato's reference to the sophists educating young men, he does not explore the possibility that Socrates is following in the sophists' footsteps.

${ }^{26}$ Ast (1816), Socher (1820), and Cholava (1858) argued against the authenticity of the Lysis because of its eristic and sophistic character, but also because of the way in which the interlocutors behave throughout the dialogue. Nevertheless, they did not consider whether or not Plato intentionally gave Lysis and Menexenus the role of the gullible young men and Socrates the role of a sophist as a warning against trusting the education of young and impressionable men to sophists.

${ }^{27}$ As Levin $(1964,4$. n.11) observes, "hardly anyone allows such credence to the anecdote recorded by Diogenes Laertius".

${ }^{28}$ Similar observations can be made on Hippothales. As Penner and Rowe (2005, 7 n.16) point out, Hippothales "does not properly understand Socrates' questions". 
introducing an argument or express an opinion that differs from Socrates' ${ }^{29}$ When Socrates asks them some simple questions about themselves and their relationship, they do not hesitate to affirm that they are friends. ${ }^{30}$ Socrates does not immediately

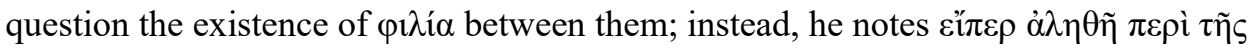

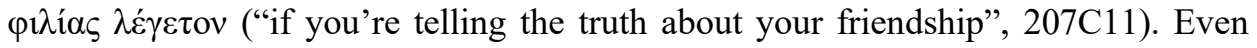
though his remark at first may appear to be a reference to the validity of their statements about their similarities, the points that he raises in later parts of the dialogue suggest that, contrary to their conviction, they may not, in fact, be pí $\lambda$ or.

Socrates stresses the value that he attaches to $\varphi(\lambda i \alpha$ by stating that from a young age he had a fervent desire to acquire friends $(211 \mathrm{E} 2-8)$. He then goes on to praise Lysis and Menexenus for having succeeded in something that he has not:

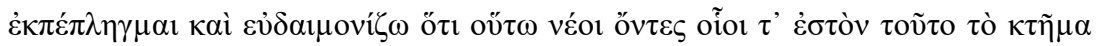

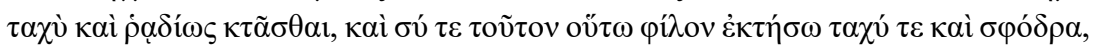

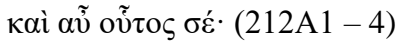

I'm overcome, and call you happy because at such a young age you're able to acquire this possession quickly and easily - you've acquired him as a friend like this, quickly and firmly, and similarly he's acquired you;

Even though his remark about Lysis and Menexenus' achievement of having found a $\varphi$ í $\chi \circ \varsigma$ in each other at first may give the impression of genuine admiration, his tone in this passage is distinctly sarcastic. ${ }^{31}$ Not only does he begin by expressing his surprise ( $\dot{\varepsilon} \kappa \pi \dot{\varepsilon} \pi \lambda \eta \gamma \mu \alpha$ ) that they are friends, but he also stresses that this has happened to two persons of such (ov๊ $\tau \omega$ ) young age. Then, in addition to the repetition of the adverb $\tau \alpha \chi v$ ('quickly'), Socrates notes that their $\varphi \imath \lambda i \alpha$ was established $\dot{\rho} \alpha \delta i ́ \omega \varsigma$ ('easily'). However, Aristotle -likely as a response to this passage- highlights the importance of time in establishing a $\varphi \imath \lambda i ́ \alpha$. He also uses $\tau \alpha \chi v$

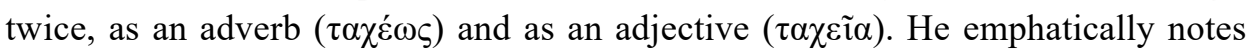

${ }^{29}$ It is worth noting that we get a sense of what kind of interlocutor Lysis will be before his dialogue with Socrates even begins. Socrates observes that Lysis is visibly interested in joining him in con-

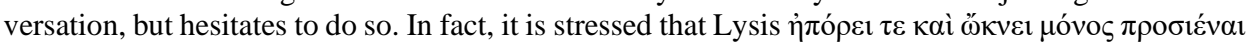
("he was at a loss about what to do, hesitating to come over to us on his own", 207A7), likely as a hint at the aporia in which the dialogue will end. Only when Menexenus sees Ctesippus and moves towards him does Lysis decide to follow him and meet Socrates. Lysis is thereby portrayed as a timid teenager who does not act or easily make decisions on his own. He is happy to follow Menexenus just like he is happy to follow Socrates' arguments without attempting a proper rebuttal.

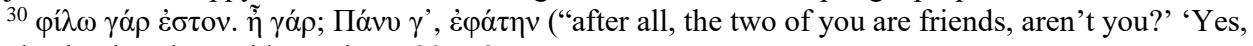
absolutely,' they said together", 207C 8 -9).

${ }^{31}$ In contrast, Glidden $(1981,39)$ does not detect sarcasm in Socrates' remark and simply notes that he congratulates them for their achievement. Penner and Rowe $(2005,49)$ offer a similar interpretation of the statement that Socrates makes. 
that while a strong desire for a $\varphi \imath \lambda i ́ \alpha$ between two persons can arise quickly, an actual $\varphi \imath \lambda i ́ \alpha$ cannot. It requires two persons to spend considerable time with one another and for their relationship to be tested before they can be considered pí $\lambda$ or (Eth. Nic. 1156b27-33). ${ }^{32}$

Apart from Aristotle, Plato in the Lysis also further suggests that Socrates' statement must have been sarcastic. The questions that Socrates poses throughout the dialogue shatter Lysis and Menexenus' pre-existing beliefs about $\varphi \imath \lambda i ́ \alpha$. The fact that Socrates returns later on to the question whether the two young men are indeed $\varphi$ í $\lambda$ or suggests that his initial reaction could not have been sincere. ${ }^{33}$ Moreover, the dialogue ends with Socrates pointing out that, despite their investigation, they were unable to

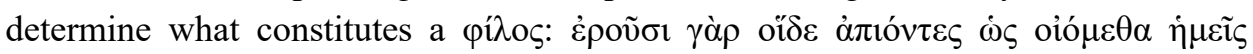

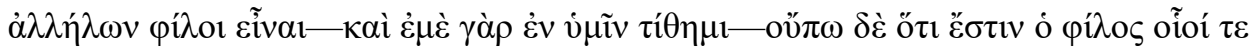

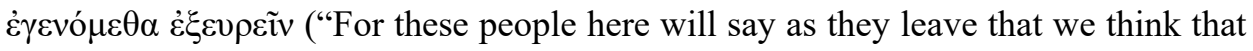
we're friends of one another - for I count myself too as one of you - but haven't yet been able to find out what the friend is", 223B5 - 8). ${ }^{34}$ This passage reveals that Lysis and Menexenus' statement about being $\varphi$ í $\lambda$ or was unfounded, since they did not -and still do not- know what a pí $\lambda$ os is. Therefore, in 212A1 - 4 Socrates either did not know if they are $\varphi$ í $\lambda \mathrm{ol}$, in which case he would not be in a position to praise them, or he did but disagreed with their belief that they are $\varphi$ í $\lambda$ ol, which would render his seemingly positive remarks about their accomplishment disingenuous. Since none of them

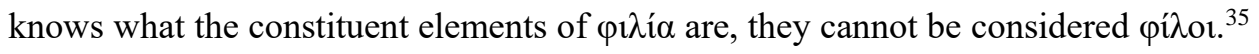
Nonetheless, Socrates maintains that the audience listening to their conversation, mainly consisting of teenagers, will leave under the impression that Socrates, Lysis, and Menexenus consider each other pí $_{01}(223 \mathrm{~B} 5-6)$. He seems to suggest on the one hand that, since they were not successful at providing a definition for $\varphi$ í $\lambda \circ \varsigma$, viewing them as $\varphi$ í $\lambda \mathrm{ol}$ would be erroneous, as was Lysis and Menexenus' initial perception of their relationship. On the other hand, his remark appears to stress the difficulties that people of such young age face when they have teachers like the pseudo-sophist Socrates of the Lysis. ${ }^{36}$ Plato thus demonstrates that teenagers, who are supposedly

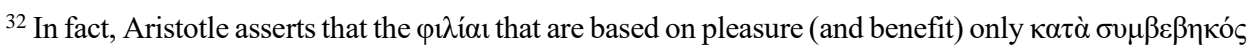

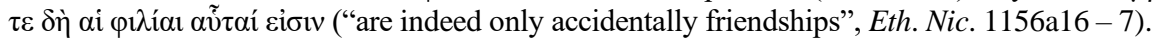

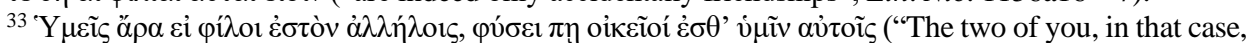
if you're friends to each other, in some way naturally belong the one to the other", 221E5 - 6).

${ }^{34}$ Crombie $(1963,20)$ provides a different interpretation of the Lysis. The fact that dialogue ends without Socrates and the two teenagers having discovered what $\varphi$ í $\lambda \circ \varsigma_{\varsigma}$ is allows the reader to draw

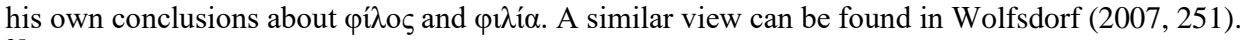
${ }^{35}$ Bosch-Veciana (1998, 112 - 113) and Penner and Rowe (2005, 49 n.26) interpret Socrates' remark as a confirmation that he considers himself a $\varphi$ í $\lambda$ os to both Lysis and Menexenus.

${ }^{36}$ I refer to Socrates as a "pseudo-sophist", because he does not fully embrace the role of a proper sophist in the dialogue. Not only does he not expect a payment for the lessons that he is teaching the
} 
being educated under sophists, could end up with false beliefs about the topics that they are being taught or, ${ }^{37}$ at the very least, more confused than they were before becoming their students. ${ }^{38}$

Plato leaves scattered throughout the dialogue plenty of hints for his readers likely his students- to realise that Socrates is speaking like a sophist. When Socrates asks Menexenus who is more noble, Menexenus himself or Lysis, he uses the verb $\dot{\varepsilon} \rho i \zeta \omega$ ("contest", 207C3) to denote the possibility that there is no consensus on the topic. Similarly, before speaking to Menexenus again, he asks Lysis whether he

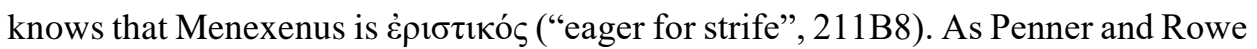
observe, the term mainly refers to sophists, as evident in the Euthydemus, in which "some professional sophists, like the brothers Euthydemus and Dionysodorus... developed it into a fine art ('eristics')". ${ }^{39}$ As the dialogue will reveal, Menexenus is by no means $\dot{\varepsilon} \rho ı \tau \tau \kappa o ́ s$, considering that he simply agrees with most of the conclusions that Socrates draws. Socrates, on the other hand, does seem to behave like an $\dot{\varepsilon} \rho ı \tau \imath \kappa o ́ \varsigma$ by displaying more interest in being correct than in discovering the truth.

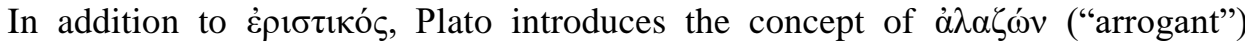

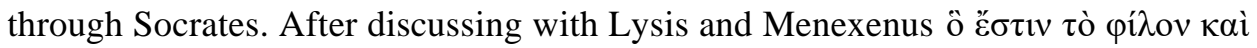

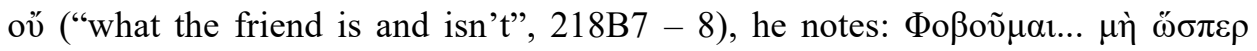

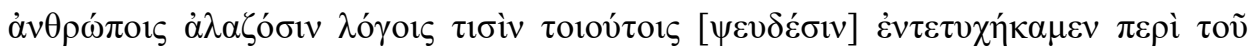

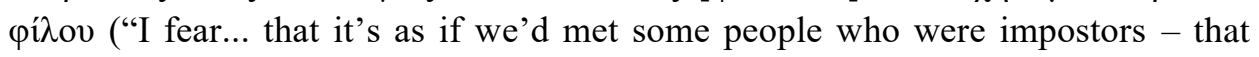
we've fallen in with a form of words about the friend that are something like that", $218 \mathrm{D} 2-4)$. His remark, at first sight, may simply give the impression that he is pointing out flaws in the way that they have conducted their research. The use of $\dot{\alpha} \lambda \alpha \zeta \hat{\omega} v$, however, is significant, because it could be a further reference to sophists. ${ }^{40}$

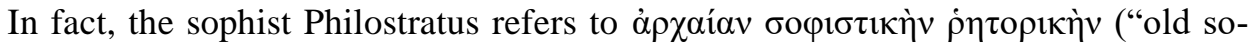

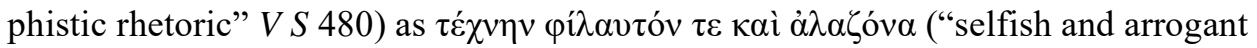
art", $V S$ 616). While Socrates uses this adjective to refer to himself as well as Lysis and Menexenus, the only person who deserves such a characterisation is Socrates whose argumentation has been distinctively sophistic. His success at persuading the two young men comes at the expense of their discovery of the truth, i.e. of the investigation into pí $\lambda$ os.

two teenagers, he also removes the cloak of the sophist every time that he draws their attention to the flaws in his arguments.

${ }^{37}$ On "corruption of youths" in the Lysis, see Ludwig (2010, 136 - 137).

${ }^{38}$ Grote $(1875,184)$ maintains that the Lysis does not provide "any positive result"; on the contrary, it ends "with speakers and hearers more puzzled than they were at the beginning". A similar view is expressed by Reshotko $(1993,1)$.

${ }^{39}$ Penner and Rowe $(2005,14)$.

40 Cratin. 380, Ar. Nub. 102, Pl. Chrm. 173c, Rep. 490a2, Xen. Mem. 1.7.5. On $\dot{\alpha} \lambda \alpha \zeta \omega \dot{\omega} v$ and $\dot{\alpha} \lambda \alpha \zeta o v \varepsilon i ́ \alpha$, see Branham $(1989,50)$ and Pangle $(2018,62-63)$. 
Perhaps an even clearer reference to sophists can be found in 216A4-B9. Before he asks Menexenus if he believes that there is something that is more opposite to $\varphi \imath \lambda i^{\alpha} \alpha$ than 'enmity' ( $\left.\varepsilon^{\prime} \chi \rho \rho \alpha\right)$, he notes that this is a question that 'antilogicians' ( $\dot{\alpha} v \tau \imath \lambda \partial \gamma(\kappa o i)$ would ask. Not only does he not hide the fact that he is following the sophists, who are notorious for using antilogic, ${ }^{41}$ he poses it as a serious question and expects an answer from Menexenus. ${ }^{42}$ Thus, a clear pattern can be observed in their discussion: Socrates develops a point, while sometimes committing a logical fallacy, and then asks Lysis and Menexenus a close-ended question. They tend to choose the second option, since the way in which Socrates phrases it gives them the impression that it is the answer that he would have chosen himself. He then rejects their answer, pointing out how problematic the conclusion, which all three of them drew, has been. It follows that, following the footsteps of sophists, such as Euthydemus and Dionysodorus ( $E u$ thyd. 273E), he is primarily concerned with refuting his interlocutors. Before he moves on to the next point, both teenagers have learned nothing about what $\varphi$ í $\lambda \circ \varsigma_{\text {is; }}$ on the contrary, they are effectively asked to reconsider the presuppositions without knowing with what to replace them.

\section{Socrates' problematic argumentation remains undetected}

Socrates uses a series of criteria to determine what $\varphi$ í $\lambda$ o $̧$ is and, although he appears to reject every trait related to the term, his arguments are in several instances evidently weak. A prime example can be found in his discussion of reciprocity among friends. ${ }^{43}$

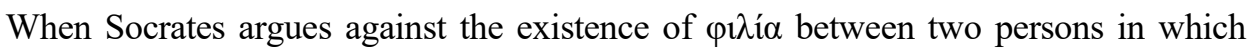
A loves B, but is not loved in return, A is loved by $\mathrm{B}$, but he does not love $\mathrm{B}$, and a mutual affection between $\mathrm{A}$ and $\mathrm{B}$, he raises valid points to highlight the incompatibility of $\varphi \imath \lambda i$ í with one-sided concern, but not the third one as well. ${ }^{44}$ Instead, he mentions among other examples- that one can be a $\varphi \imath \lambda o ́ \sigma o \varphi o \varsigma$ or a $\varphi$ í loves $\left(\varphi \lambda \lambda \varepsilon \dot{\varepsilon 1)}\right.$ wisdom or wine, but wisdom and wine do not love one in return. ${ }^{45}$

${ }^{41}$ As Kerferd (1981, 61 - 62) observes, in Plato's works, antilogic is closely associated with the sophists. This is particularly evident in Soph. 225A12-226A5.

${ }^{42}$ The antilogic that Socrates uses is also discussed in Penner and Rowe (2005, 97 -98).

${ }^{43}$ Reshotko (1997, 2 - 3) points out that reciprocity does not appear to be an integral part of $\varphi 1 \lambda i ́ \alpha$ in Plato's Lysis. Penner and Rowe $(2005,56)$ express the same view. In contrast, Ludwig $(2010$, 138 ) notes that the utilitarian nature of $\varphi \imath \lambda i$ i in the Lysis would be considered "extreme" even in Plato's time.

${ }^{44}$ von Arnim $(1914,46)$ argues that Socrates' statements in the Lysis are not all meant be taken seriously.

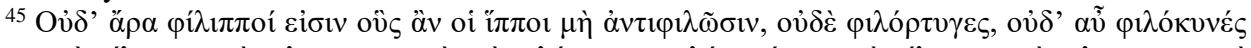

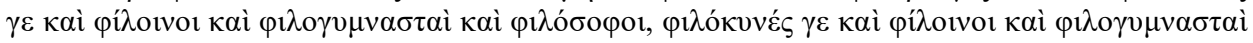

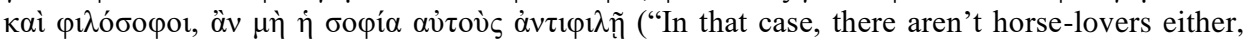
when the horses don't love them back, or quail-lovers, or for that matter dog-lovers and winelovers and exercise-lovers and wisdom-lovers - unless wisdom loves them in return", 212D5 - 9). 
Socrates thus commits a logical fallacy; ${ }^{46}$ comparing affection between a person with affection towards or from an object is a clear case of fallacy of equivocation. ${ }^{47}$ Nevertheless, Menexenus fails to provide a counter argument or to point out the blatant flaw in Socrates' absurd argumentation. ${ }^{48} \mathrm{He}$ simply agrees with him (212D8 -9).$^{49}$ Lysis is portrayed as an equally naive teenager who is so eager to learn from an authority figure that the possibility of challenging Socrates does not seriously cross his mind. When Socrates discusses with Lysis his parents' love and affection for him, he asks him why his parents do not trust him with their affairs. Lysis assumes that it is a matter of knowledge. The points that Socrates provides to refute his argument are unequivocally a case of reductio ad absurdum. For instance, no one would believe that the great king of Asia would trust Lysis over his own son for the preparation of meat, even if he deemed Lysis more knowledgeable. Nevertheless, Lysis does not disagree with Socrates nor does he point out the absurdity of Socrates' remarks. ${ }^{50}$

Lysis and Menexenus' inability to see through Socrates' weak arguments forces Socrates himself to point out the flaws of their discussion to them as well as to the rest of the teenagers listening to their conversation. In numerous occasions, Socrates notes that they have contradicted themselves $(212 \mathrm{D} 1-3,222 \mathrm{D} 1-3,7-8)$ and that they have not conducted their research properly $(213 \mathrm{D} 1-2) .{ }^{51}$ By making these remarks, Socrates draws attention both to the points that he raises and to the young men's answers. The language employed suggests an effort to warn them that his line of thought is problematic and that they need to reconsider the way in which they process information. The adjective $\kappa \alpha \tau \alpha \gamma \varepsilon \dot{\lambda} \alpha \sigma \tau \sigma$ ("ridiculous") is used in different parts of the dialogue to highlight the absurdity of the discussion taking place. ${ }^{52}$ Interestingly, it is first introduced at the beginning of the dialogue when Ctessipus, in his brief discussion with

${ }^{46}$ As Kerferd (1981, 62 - 63) rightly observes, sophists in Plato's dialogues that use the art of eristic are not necessarily concerned with the truth, hence their reliance on fallacies as tools to secure victory in their debates.

${ }^{47}$ Penner and Rowe $(2005,53$ - 55) argue against such a reading of the passage.

${ }^{48}$ Glidden (1981, 39 n.9) also maintains that Socrates' argument is simply absurd. For other examples of problematic argumentation in the Lysis, see Glidden $(1981,45)$ and Ludwig $(2010,137)$.

49 On Menexenus' insistence on agreeing with almost everything that Socrates says, see Glidden (1981, 42 n.32).

${ }^{50}$ Hetherington (2009, 69-70) observes that "as Socrates suggests more outrageous ideas Lysis continues to agree" in his effort "to hold on to a stated position". However, this view cannot easily be entertained considering that Lysis consistently agrees with the vast majority of Socrates' statements in the dialogue and not only in this particular case.

${ }^{51}$ On the many contradictions in the Lysis and inconsistencies with other Platonic dialogues, see Shorey $(1930,382)$ and Wolfsdorf $(2004,33)$. According to Glidden (1981, 44 n.56), "Plato does mention in the Lysis views which we know he did not himself accept". Annas (1977, 533, 539) attributes the inconsistencies displayed in the Lysis to the "different uses" of the term pi $\lambda$ ía.

52 It is perhaps worth mentioning that a TLG search reveals that $\kappa \alpha \tau \alpha \gamma \varepsilon \dot{\varepsilon} \alpha \sigma \tau ం \varsigma$ can be found 54 times in the Platonic corpus, mostly as an adjective, but also in its adverbial form. 
Socrates, refers to Hippothales' unrequited love for Lysis twice as "ridiculous"

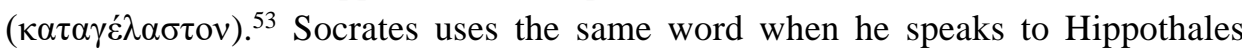
about the songs that he writes for Lysis. He refers to him as $\kappa \alpha \tau \alpha \gamma \varepsilon \dot{\lambda} \alpha \sigma \sigma \tau \mathrm{s}$ (205D5, 206A1) because, according to Socrates, he does not realise that these songs are a form of self-praise rather than praise for his loved one. The adjective reappears later on when Socrates is about to speak with Menexenus. After Socrates notes that

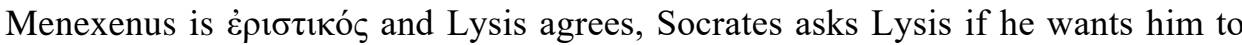

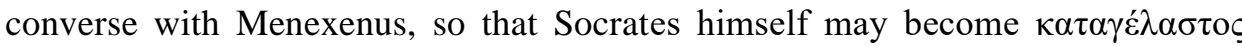
(211B8 - C2). Through the argumentation that he employs in the dialogue, Socrates

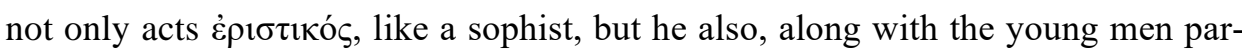
ticipating in or listening to the conversation, becomes $\kappa \alpha \tau \alpha \gamma \varepsilon \dot{\varepsilon} \lambda \alpha \sigma \tau$ oc. This is lucidly expressed at the end of the dialogue. After their entire discussion of $\varphi$ í $\lambda \circ \varsigma$, Socrates

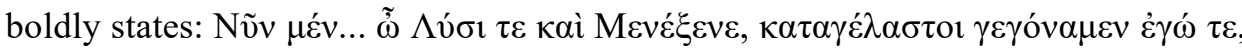

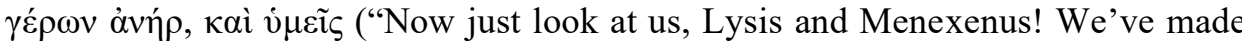
ourselves ridiculous, I, an old man, and you too", 223B4 - 5). His observation is significant because the reader of the Lysis is left with the impression that the preceding discussion cannot be considered a serious treatment of $\varphi$ í $\lambda \sigma_{\varsigma}$ and $\varphi \imath \lambda i ́ \alpha$. While Socrates became $\kappa \alpha \tau \alpha \gamma \varepsilon \dot{\varepsilon} \lambda \alpha \sigma \tau$ o $\zeta$ because of his absurd argumentation, the two young men, deserve the epithet $\kappa \alpha \tau \alpha \gamma \varepsilon \dot{\varepsilon} \alpha \sigma \tau$ o because of their failure to diverge from Socrates or to point out the flaws in the points that he raises. Therefore, just like Hippothales, whose infatuation with Lysis made him ridiculous, so were Lysis and Menexenus, because of their reluctance to express a disagreement with someone whom they admired and considered wise.

Socrates' efforts to alert his interlocutors about the direction of their discussion were not limited to stressing the absurdity of his remarks. In addition to attacking one

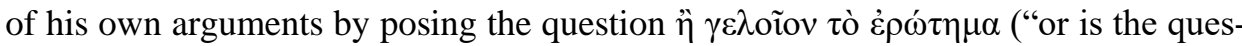
tion... ridiculous", 221A4), he refers to one of the conclusions, which they have drawn about what $\varphi \hat{i} \lambda o \varsigma$ is, as an $00 \lambda_{0} \varsigma$ ('nonsense'). ${ }^{54}$ Perhaps the most significant aspect of the dialogue that suggests an attempt to protect teenagers from awe-inspiring men is the emphasis that it places on deception. Socrates repeatedly manages to deceive Lysis and Menexenus, while the young men are completely unaware of his

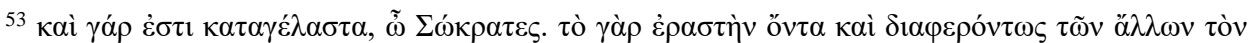

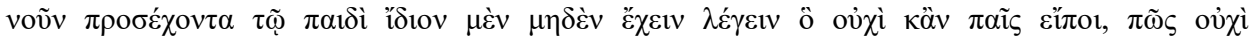
$\kappa \alpha \tau \alpha \gamma \varepsilon \dot{\lambda} \alpha \sigma \tau \mathrm{OV}$; ("Because the things he says are ridiculous into the bargain, Socrates. He's a lover, with his mind fixed more than anyone else's on the boy, and yet he doesn't have anything of his own to say that even - a boy couldn't say: is that ridiculous, or isn't it?", 205B6 - C2).

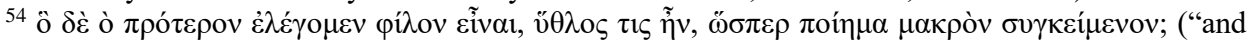
that what we were previously saying being a friend was, was some kind of nonsense, like a poem that's been badly put together?", 221D4 - 6). 
intentions ${ }^{55}$ Because of their tendency to agree with him, even when his arguments become absurd, Socrates momentarily breaks character in many occasions throughout the Lysis by abandoning the persona of the skilful, yet deceitful sophist. He reverts to the kind of philosopher that Socrates is known for in the Platonic dialogues, i.e. someone who is genuinely interested in helping his interlocutors. Although he does not outright admit that he has been successful at deceiving them, he stresses in four occasions that all three of them have been deceived.

After arguing that good men would not be friends with other good men because they are self-sufficient, Menexenus assents instead of providing a counter argument, which prompts Socrates to ask him to consider the possibility that they are mistaken and that $\tilde{\alpha} \rho \alpha \dot{\gamma} \gamma \varepsilon$ ö $\lambda \omega \tau \imath v \grave{\varepsilon} \xi \dot{\xi} \alpha \pi \alpha \tau \omega \dot{\omega} \varepsilon \theta \alpha$; ("Is it even that there's a way we're being deceived completely?", 215B3 - C4). He uses the same terminology when Menexenus agrees with a view about similarity that Socrates expresses, despite the fact that this view had already been rejected by both of them earlier. Menexenus had clearly been deceived by Socrates and since he does not realise this, Socrates needs to draw his attention to their earlier findings. ${ }^{56}$ While he uses the first-person plural $(\mu$ iे $\dot{\varepsilon} \xi \alpha \pi \alpha \tau \eta \theta \tilde{\omega} \mu \varepsilon v)$, he is undoubtedly referring solely to the two young men who are repeatedly being tricked by him. In just a few lines, he, once again, strongly advises exercising caution from this point on to avoid being deceived ${ }^{57}$ Considering that he is in complete control of the conversation, it would follow that the person of whom they need to be wary is Socrates himself. The last instance in which the verb $\dot{\varepsilon} \xi \alpha \pi \alpha \tau \tilde{\alpha} v$ is used in the dialogue is, perhaps, the most impactful. Towards the end of the dialogue, Socrates makes a particularly bold statement: he rejects the entire discussion that has taken place hitherto by referring to the previous points made as $\varepsilon$ ei $\delta \omega \lambda \alpha$ ('phantoms') that have deceived them and by arguing that, in order to un-

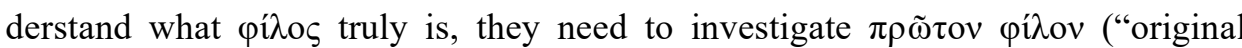
friend", 219C4 - D5). Not only does his remark imply that Socrates has been deceiving Lysis and Menexenus throughout most of the dialogue, but also that the

\footnotetext{
${ }^{55}$ Weiss $(2001,10$ - 11) observes Socrates' intention to deceive in the Meno, but stresses the difference between his and the sophists' intentions. Accusations against the sophists for their tendency to deceive people, in order to achieve their goal, can also be found in Pl. Prt. 313C, Isoc. C. soph. 291, and Xen. Cyn. 13.8.

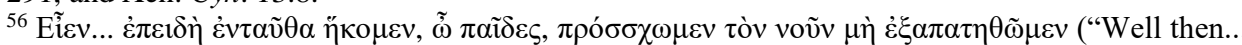
now that we've got here, boys, let's pay attention to avoid our being deceived", 219B5 - 6).

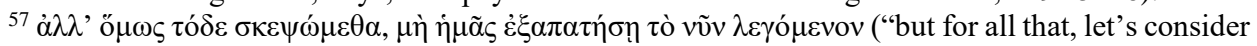
the following, to prevent what we are saying now from deceiving us". 219B8-C1).
} 
readers should disregard anything they think that they learned about pí $\lambda$ os since the beginning of the Lysis. ${ }^{58}$

Right before the end of the dialogue, Socrates gives Lysis and Menexenus one last opportunity to prove that they can think independently instead of saying what they think Socrates wants to hear. He offers them two options:

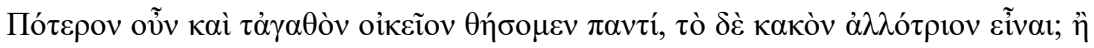

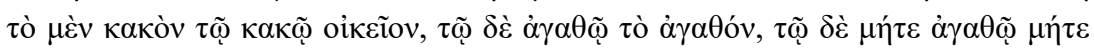

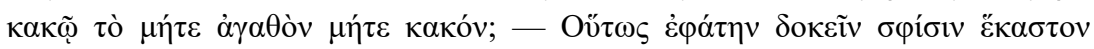

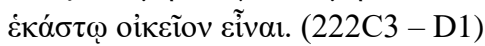

"Shall we then also lay it down that the good belongs to everyone, and the bad is alien? Or that the bad belongs to the bad, to the good the good, and to the neither good nor bad the neither good nor bad?" They both said it seemed to them like this, that each belongs to each.

Their answer follows the pattern that they have used throughout the dialogue, i.e. to either agree with Socrates or to choose the last option provided, under the impression that that would be Socrates' choice as well. Out of the two options they have to choose from, the former, i.e. the good being oikciov ('belongs') to everyone, has not been argued against, while the latter, i.e. similarity determining if something is

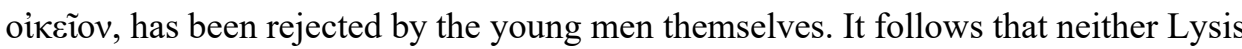
nor Menexenus is able to comprehend the topic they have been discussing and all its nuances. ${ }^{59}$ Socrates' complex and problematic argumentation becomes impossible to follow and, even though Lysis and Menexenus are impressed by Socrates, in terms of education, they are worse off after their discussion, since, when they met Socrates, they were at least under the impression that they were friends. After the end of the dialogue, considering that they have not reached a conclusion on what makes one a $\varphi$ í $\lambda$ o or at least what some of its constituent elements are, they are no longer able to state with certainly that they are $\varphi$ í $\lambda$ or. The confusion that Socrates has caused is a detriment to their attainment of wisdom. Every time that Socrates tests them by arguing for a position that they had already dismissed, they fail to provide the correct answer, as they simply do not realise about what they are agreeing. Socrates, the pseudo-sophist, is proven successful at deceiving them consistently throughout the

${ }^{58}$ Nevertheless, despite Socrates rejecting his own arguments, as Wolfsdorf (2007, 237 - 239) rightly observes, the view of $\varphi \imath \lambda i \alpha$ as something beneficial and $\varphi \imath \lambda i ́ \alpha$ existing between someone who is neither good nor bad and someone who is good remain unchallenged throughout the dialogue.

${ }^{59}$ Penner and Rowe $(2005,174$ - 179) hold a distinctly different view. They argue that the two teenagers display independent thinking and they attribute their decision to choose the second option to their reluctance to abandon their previous position. 
dialogue. Lysis and Menexenus fail to detect his intention to trick them and, up until the end of the Lysis, they show no signs that their interaction with this kind of Socrates has been of any value to them. ${ }^{60}$

In conclusion, in the Lysis Plato appears to be using the dialogue in an effort to demonstrate the problems that can arise when parents fully entrust their children to men like the sophists. The youths have a propensity to agree with their every word, but, unlike the Socrates of the Lysis, such men would not point out to them that their own argumentation is flawed or that they are deceiving them. Hence Socrates being forced repeatedly to switch roles from pseudo-sophist to the Socrates of the later dialogues. Both Lysis and Menexenus fail to see through the sophistry in his argumentation and to comprehend that he has become an eristic by being solely interested in winning the debate instead of discovering the truth of what pí $\lambda$ os is. More importantly, they fail to pick up the hints that Socrates spreads throughout the dialogue, especially with the language that he uses ( $\dot{\varepsilon} \xi \alpha \pi \alpha \tau \eta \theta \tilde{\omega} \mu \varepsilon v$, $v \theta \lambda \circ \zeta$,

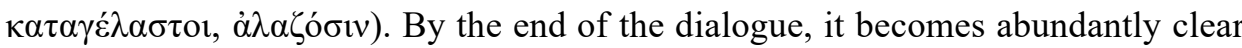
that no matter how many times Socrates makes baseless statements, the two young men will not challenge him, but will simply agree with him before and after he comments on the mistake that he made. It is thus implicitly suggested that caution needs to be exercised when parents choose their children's educators. While Lysis and Menexenus represent young men, who study philosophy and rhetoric but are too gullible to question their teachers, Plato's students were likely trained, especially through the Lysis, to identify cases of weak argumentation and to challenge their educators when they deemed necessary.

\section{Bibliography}

ANNAS, J. (1977): Plato and Aristotle on Friendship and Altruism. Mind, 86 (344), 532 - 554. AST, F. (1816): Platons Leben und Schriften. Leipzig.

BLANK, D. L. (1985): Socratics versus Sophists on Payment for Teaching. Classical Antiquity, 4, 1 - 49. BOLOTIN, D. (1977): Plato's Dialogue on Friendship. An Interpretation of the Lysis with a New Translation. Ithaca - London: Cornell University Press.

BOSCH-VECIANA, A. (1998): Plato's Lysis: Aporia and Dialectic Logoi Friendship «Realized» all throughout the Dialogue. Revista catalana de teología, 23 (1), 109 - 118.

BRANHAM, R. B. (1989): Unruly Eloquence: Lucian and the Comedy of Traditions. Cambridge Mass - London: Harvard University Press.

BURY, R. G. (1910): The Ethics of Plato. International Journal of Ethics, 20 (3), 271 - 281.

CHOLAVA, S. (1858): Über die Unechtheit des Dialogs Lysis. Zeitschrift für die Österreichischen Gymnasien, 9, $793-802$.

${ }^{60}$ O'Grady $(2008,127)$ makes a similar observation on Euthydemus by arguing that the sophists of the dialogue have nothing to offer to their interlocutor because of the complete absence of wisdom in their argumentation. 
CROMBIE, I. M. (1962): An Examination of Plato's Doctrines. Vol.1. London: Routletge.

DIRLMEIER, F. (1931): Philos und Philia im vorhellenistischen Griechentum. München: Druck der Salesianischen Offizin.

EL MURR, D. (2014): Philia in Plato. In: Stern-Gillet, S. - Gurtler, G. M. (eds): Ancient and Medieval Concepts of Friendship. Albany: State University of New York Press, 3 - 34.

GLIDDEN, D. K. (1981): The Lysis on Loving One's Own. Classical Quarterly, 31 (1), 33 - 59.

GROTE, G. (1875): Plato and the other Companions of Socrates. London: John Murray.

GUTHRIE, W. K. C. (1975): A History of Greek Philosophy IV. Plato: The Man and his Dialogues. Cambridge: Cambridge University Press.

HADEN, J. (1983): Friendship in Plato's Lysis. Review of Metaphysics, 37 (2), 327 - 356.

HARRISON, E. L. (1964): Was Gorgias a Sophist? Phoenix, 18 (3), 183 - 192.

HETHERINGTON, E. D. (2009): [diss.], Philia and Method: A Translation and Commentary on Plato's Lysis. New York: The City University of New York.

HOERBER, R. G. (1959): Plato's Lysis. Phronesis, 4 (1), 15 - 28.

KERFERD, G. B. (1981): The Sophistic Movement. Cambridge: Cambridge University Press.

KONSTAN, D. (1996a): Friendship from Epicurus to Philodemus. In: Giannantoni, M. - Gigante, M. (eds), L'Epicureismo greco e romano. Naples: Bibliopolis, 387 - 396.

KONSTAN, D. (1996b): Greek Friendship. American Journal of Philology, 117 (1), 71 - 94.

KONSTAN, D. (1997): Friendship in the Classical World. Cambridge: Cambridge University Press.

LAMB, W. R. M. (1952): Plato: Laches. Protagoras. Meno. Euthydemus with an English translation. Cambridge - Mass.: Harvard University Press.

LEVIN, D. N. (1964): Some Observations Concerning Plato's Lysis. The Society for Ancient Greek Philosophy Newsletter, 36, 1 - 29.

LUDWIG, P.W. (2010): Without Foundations: Plato's Lysis and Postmodern Friendship. The American Political Science Review, 104 (1), 134 - 150.

LUTOSLAWSKI, W. (1897): The Origin and Growth of Plato's Logic, with an Account of Plato's Style and of the Chronology of his Writings. London, Longmans, Green, and co.

MACKENZIE, M. M. (1985): Plato's Moral Theory. Journal of Medical Studies, 11, 88 - 91.

NICHOLS, M. P. (2006): Friendship and Community in Plato's Lysis. Review of Politics, 68 (1), 1 - 19.

O'GRADY, P. F. (2008): The Sophists: An Introduction. London: Duckworth.

PANGLE, T. L. (2018): The Socratic Way of Life: Xenophon's Memorabilia. Chicago: University of Chicago Press.

PENNER, T., ROWE, C. (2005): Plato's Lysis. Cambridge: Cambridge University Press.

PLANEAUX, C. (2001): Socrates an Unreliable Narrator? The Dramatic Setting of the Lysis. Classical Philology, 96, 60 - 68.

POHLENZ, M. (1913): Aus Platos Werdezeit. Berlin: Weidmannsche Buchhandlung.

IRWIN, T.H. (1995): Plato's objections to the sophists. In: A. Powell (ed.): The Greek World. London - New York: Routledge.

PRICE, A. W. (1990): Love and Friendship in Plato and Aristotle. Oxford: Clarendon Press.

RESHOTKO, N. (1993): The Socratic Theory of Motivation. Apeiron, 25, 145 - 170.

RESHOTKO, N. (1997): Plato's Lysis: a Socratic Treatise on Desire and Attraction. Apeiron, 30 (4), $1-18$

SERMAMOGLOU-SOULMAIDI, G. (2014): Playful Philosophy and Serious Sophistry: A Reading of Plato's Euthydemus. Berlin - Boston: Walter de Gruyter.

SHOREY, P. (1930): The Alleged Fallacy in Plato Lysis 220 E. Classical Philology, 25 (4), 380 383.

SOSCHER, J. (1820): Über Platons Schriften. Munich: Lentner.

TAYLOR, A. E. (1949): Plato the Man and his Work. London: Buttler and Tanner. 
TELL, H. (2009): Wisdom for Sale? The Sophists and Money. Classical Philology, 104 (1), $13-33$

VERSENYI, L. (1975): Plato's Lysis. Phronesis, 20 (3), 185 - 198.

VON ARNIM, H. (1914): Platos Jugenddialoge und die Entstehungszeit des Phaidro. Leipzig: Teubner.

VLASTOS, G. (1973): Platonic Studies. Princeton: Princeton University Press.

VLASTOS, G. (1991): Socrates: Ironist and Moral Philosopher. Ithaca: Cornell University Press. WEISS, R. (2001): Virtue in the Cave: Moral Inquiry in Plato's Meno. Oxford University Press. WOLFSDORF, D. (2004): Interpreting Plato's Early Dialogues. Oxford Studies in Ancient Philosophy, 27, $15-40$.

WOLFSDORF, D. (2007): Philia in Plato's Lysis. Harvard Studies in Classical Philology, 103, $235-259$.

This paper was supported by the scientific project VEGA 1/0864/18: Ad Fontes Cynicorum Socraticorum - pramene a interpretácia sokratovského kynizmu.

Gabriel Evangelou

Postdoctoral researcher

University of Cyprus

Department of Classics and Philosophy

P.O. Box 20537

1678 Nicosia

Cyprus

Email: evangelou.gabriel@ucy.ac.cy

ORCID ID: https://orcid.org/0000-0001-5470-1097 